\title{
Transcriptional regulatory networks controlling woolliness in peach in response to preharvest gibberellin application and cold storage
}

\author{
Camila Pegoraro ${ }^{1,2}$, Alice Tadiello 3,4 , César L. Girardi ${ }^{5}$, Fábio C. Chaves ${ }^{6}$, Vera Quecini ${ }^{5}$, Antonio Costa de Oliveira ${ }^{1}$, \\ Livio Trainotti ${ }^{3}$ and Cesar Valmor Rombaldi ${ }^{6^{*}}$
}

\begin{abstract}
Background: Postharvest fruit conservation relies on low temperatures and manipulations of hormone metabolism to maintain sensory properties. Peaches are susceptible to chilling injuries, such as 'woolliness' that is caused by juice loss leading to a 'wooly' fruit texture. Application of gibberellic acid at the initial stages of pit hardening impairs woolliness incidence, however the mechanisms controlling the response remain unknown. We have employed genome wide transcriptional profiling to investigate the effects of gibberellic acid application and cold storage on harvested peaches.
\end{abstract}

Results: Approximately half of the investigated genes exhibited significant differential expression in response to the treatments. Cellular and developmental process gene ontologies were overrepresented among the differentially regulated genes, whereas sequences in cell death and immune response categories were underrepresented. Gene set enrichment demonstrated a predominant role of cold storage in repressing the transcription of genes associated to cell wall metabolism. In contrast, genes involved in hormone responses exhibited a more complex transcriptional response, indicating an extensive network of crosstalk between hormone signaling and low temperatures. Time course transcriptional analyses demonstrate the large contribution of gene expression regulation on the biochemical changes leading to woolliness in peach.

Conclusion: Overall, our results provide insights on the mechanisms controlling the complex phenotypes associated to postharvest textural changes in peach and suggest that hormone mediated reprogramming previous to pit hardening affects the onset of chilling injuries.

Keywords: Chilling injury, Cold storage, Genome wide gene expression, Gibberellic acid, Prunus persica

\section{Background}

Typically, the shelf life of peach fruit (Prunus persica L. Batsch.) is short due to its fragility, fast loss of pulp firmness and decay susceptibility. Thus, postharvest conservation is based on methods that decrease pathogen inocula, and reduce fruit metabolism [1]. Cold storage (CS) has been the main method used to increase peach shelf life. However, a wide range of factors, such as

\footnotetext{
*Correspondence: cesarvrf@ufpel.edu.br

${ }^{6}$ Departament of Food Science and Technology, Universidade Federal de Pelotas, Campus UFPel Capão do Leão, Pelotas, RS 96010-900, Brazil Full list of author information is available at the end of the article
}

cultivar, ripening stage at harvest, temperature and time of storage, contribute to the occurrence of physiological disorders, commonly known as chilling injury, including woolliness or loss of juice, pit darkening and reddening, flesh breakdown and others $[2,3]$.

In peaches, woolliness occurrence is frequent after long-term CS, even when the fruits are kept at temperatures as low as $0{ }^{\circ} \mathrm{C}[4-7]$. Chilling injuries are complex phenotypes, likely to be controlled by a wide range of genetic, developmental, anatomical and physiological factors $[2,3,8,9]$. Exogenous application of GA to peach and nectarine fruits on the tree at the initial stages of pit 
hardening has been demonstrated to effectively reduce woolliness incidence $[3,5,6]$. Preharvest hormone application has been demonstrated to reduce chilling injuries a reduced number of cultivars, such as Chimarrita and Chiripá $[3,5,6]$. The responses induced by the hormone that lead to the reduced occurrence of the woolly phenotype remain largely unknown. Exogenous GA application in citrus has been demonstrated to induce pleiotropic and previously unreported effects [10].

Pectin metabolism is currently considered one important effector of woolliness in peach [2], although the molecular mechanisms involved in its onset remain elusive. Reduced accumulation of transcripts from genes related to normal ripening processes, such as those involved in ethylene biosynthesis and signaling, cellular respiration, volatile compounds biosynthesis, endocellular transport, protein folding, lipid turnover, cell wall disassembling and redox system, has been correlated to chilling disorders [11-18]. The abnormal ripening processes under cold storage are thought to trigger wooliness at the transcriptional level. Targeted proteomic approaches have also demonstrated similar behavior of protein and enzyme activity levels $[1,5]$.

In the current work, we have taken advantage of the GA-responsive genomic context, consisting of the cultivar Chimarrita, to investigate the large-scale transcriptional profile of peaches, subjected to hormone application at the initial stages of pit hardening, at harvest and after chilling injury inducing storage conditions. In addition, time course analyses of the woolly phenotype development and candidate gene expression were performed on
GA-treated and control fruits submitted to CS, before the onset of the disturbance. Taken together, our results demonstrate that a complex interplay between transcriptional programs controlled by GA and low temperatures underlies cellular and developmental mechanisms associated to woolliness in peaches.

\section{Results}

Application of GA at pit hardening stage reduces woolliness The incidence of woolliness remained undetected for control and GA treated fruits up to 15 days under CS (Fig. 1). After this period, the frequency of woolly fruits steeply increased in untreated control peaches (Fig. 1). Preharvest application of exogenous GA significantly prevented the incidence of woolliness after CS (Fig. 1). After 30 days under CS and two days at RT, approximately $100 \%$ of the control fruits exhibited the physiological disorder (Fig. 1). In contrast, the incidence of woolliness in fruits harvested from trees sprayed with GA at the onset of pit hardening was more than six fold smaller (16 \%) (Fig. 1).

\section{Genome wide transcriptional profiling of peach under postharvest conditions}

Genome wide expression analyses, employing 28,689 protein-coding transcripts from the peach transcriptome were performed for control and GA treated fruit at harvest and after CS. Factorial analysis of the expression data revealed extensive transcriptional changes in response to CS and GA, with $48.26 \%$ (13846) of the genes being differentially expressed (Fig. 2, Additional file 1: Table S1).

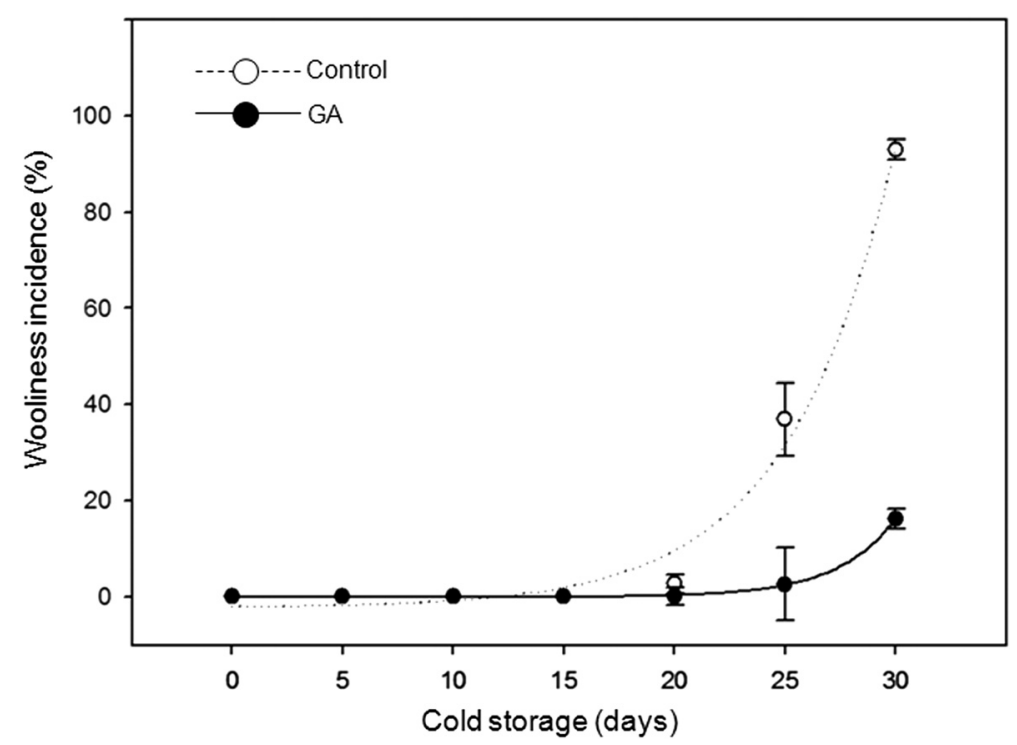

Fig. 1 Woolliness symptom occurrence in preharvest GA untreated (Control) and GA treated peaches (GA). Fruits were stored for 30 days under cold storage (CS $-0 \pm 0.5^{\circ} \mathrm{C}$ and $90 \pm 5 \%$ of relative humidity) and ripened at room temperature (RT $\left.-25 \pm 2{ }^{\circ} \mathrm{C}\right)$ for 2 days. The GA treatment was carried out in the pre harvest before pit hardening of peaches 
From overlap analysis, approximately $34 \%$ of the genes exhibiting differential expression in response to the tested factors (GA, CS) were commonly down (35.4\%, 4912) and $(33.63 \%, 4657)$ up regulated (Fig. 2), although induction and/or repression levels were significantly different between GA and CS. Gene sets exhibiting exclusive regulation by CS or GA were also detected (Fig. 2). A subset of transcripts exhibit opposite responses to GA and CS treatments, being $17.23 \%$ (2386) induced by GA and repressed by CS (Fig. 2) and $13.7 \%$ (1891) repressed by GA and induced by CS (Fig. 2).

Differentially regulated genes classified to gene ontology (GO) classes of cellular, metabolic and developmental processes were significantly overrepresented in comparison to reference peach transcriptome (Table 1, Fig. 3). In contrast, GO classes corresponding to cell death and immune system responses were underrepresented in all investigated conditions (Table 1, Fig. 3). Metabolic classification of the genes exhibiting significant responses to GA and CS according to the MapMan scheme revealed transcriptional shifts associated to primary and specialized metabolism (Fig. 4), with a predominantly repressive effect of CS on global gene expression. CS and GA treatment significantly affected the expression of the coding sequences for a wide range of cell wall metabolism associated proteins, such as cellulose syntases, pectinesterases, polygalacturonases, pectate lyases, xyloglucan endotransglycosyilases and expansins (Fig. 4). Similarly, genes associated to carbohydrate, lipid, specialized metabolism, amino acids, nucleotides, fermentation, tetrapyrrole and photorespiration (Fig. 4) were distinctly regulated in response to low temperatures and GA treatment.

A large number of genes associated to photosynthesis light reactions were differentially regulated in peach fruit in response to CS and GA application (Fig. 4). The application of GA and storage of fruit under CS promoted the differential expression of sequences coding for light harvesting complexes, photosystem II reaction centers, photosystem II core complexes, photosystem I subunits and photosystem II subunits (Fig. 4).

\section{Gene set enrichment analyses (GSEA) of woolliness associated candidate probes}

To gain insight in the processes associated to the onset of woolliness, we have investigated the transcriptional behavior of genes known to be involved in cell wall metabolism and hormonal regulation by gene set enrichment analyses (GSEA). Eight distinct expression patterns were identified by clustering analyses of the transcriptional behavior of cell wall metabolism genes in peach in response to CS and GA. Exogenous GA application repressed the expression of a subset of genes in the first two clusters. A third subset of cell wall associated genes,

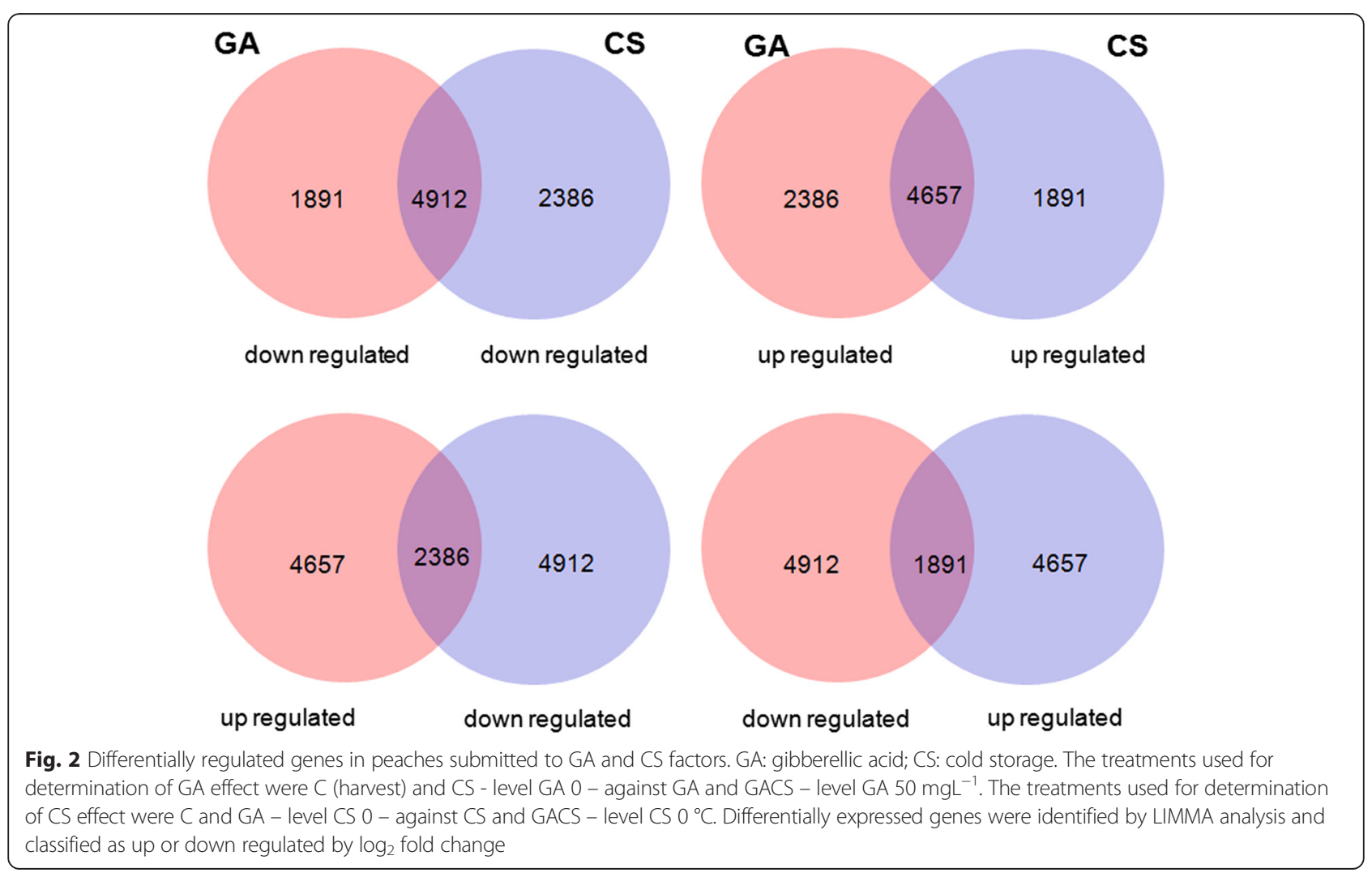


Table 1 Parametric analysis of gene set enrichment of GO terms in response to GA and CS

\begin{tabular}{|c|c|c|c|c|c|c|}
\hline \multirow[b]{2}{*}{ GO class } & \multirow[b]{2}{*}{ Description } & \multicolumn{2}{|l|}{ Number } & \multirow[b]{2}{*}{ Enrichment fold } & \multirow[b]{2}{*}{$p$-value } & \multirow[b]{2}{*}{$\mathrm{FDR}^{\mathrm{a}}$} \\
\hline & & $\begin{array}{l}\text { Differentially expressed } \\
(13870)\end{array}$ & $\begin{array}{l}\text { Reference genome } \\
\text { (28702) }\end{array}$ & & & \\
\hline \multicolumn{7}{|c|}{ Biological process } \\
\hline GO:0006412 & translation & 323 & 396 & 2.268725143 & 4.30E-27 & $1.50 \mathrm{E}-23$ \\
\hline GO:0009987 & cellular process & 2356 & 5297 & 1.237142882 & 1.30E-21 & $2.40 \mathrm{E}-18$ \\
\hline GO:0044237 & cellular metabolic process & 1887 & 4133 & 1.269933684 & 1.40E-20 & $1.70 \mathrm{E}-17$ \\
\hline GO:0008152 & metabolic process & 2703 & 6308 & 1.191870055 & $3.20 \mathrm{E}-18$ & $2.80 \mathrm{E}-15$ \\
\hline GO:0044267 & cellular protein metabolic process & 890 & 1791 & 1.382193889 & 5.60E-16 & $3.90 \mathrm{E}-13$ \\
\hline GO:0009058 & biosynthetic process & 1038 & 2202 & 1.311156664 & 7.80E-14 & 4.60E-11 \\
\hline GO:0044249 & cellular biosynthetic process & 968 & 2075 & 1.297573011 & 3.80E-12 & 1.90E-09 \\
\hline GO:0044281 & small molecule metabolic process & 317 & 558 & 1.580154713 & 8.10E-11 & 3.60E-08 \\
\hline GO:0010467 & gene expression & 747 & 1589 & 1.307588981 & 4.80E-10 & $1.80 \mathrm{E}-07$ \\
\hline GO:0019538 & protein metabolic process & 1022 & 2273 & 1.250621837 & 5.10E-10 & 1.80E-07 \\
\hline \multicolumn{7}{|c|}{ Molecular function } \\
\hline GO:0003735 & structural constituent of ribosome & 234 & 265 & 2.456091438 & $5.60 \mathrm{E}-23$ & 1.20E-19 \\
\hline GO:0005198 & structural molecule activity & 252 & 303 & 2.313302674 & $3.30 \mathrm{E}-22$ & 3.60E-19 \\
\hline GO:0003824 & catalytic activity & 2579 & 6355 & 1.128782675 & 2.30E-09 & $1.70 \mathrm{E}-06$ \\
\hline GO:0016874 & ligase activity & 146 & 246 & 1.650791775 & 1.60E-06 & 0.00087 \\
\hline GO:0019001 & guanyl nucleotide binding & 121 & 212 & 1.587537735 & 4.30E-05 & 0.017 \\
\hline GO:0032561 & guanyl ribonucleotide binding & 119 & 209 & 1.58370841 & 5.40E-05 & 0.017 \\
\hline GO:0005525 & GTP binding & 119 & 209 & 1.58370841 & 5.40E-05 & 0.017 \\
\hline GO:0016879 & ligase activity, forming carbon-nitrogen bonds & 100 & 171 & 1.626591271 & 9.70E-05 & 0.026 \\
\hline \multicolumn{7}{|c|}{ Cellular component } \\
\hline GO:0005622 & intracellular & 1106 & 2064 & 1.490458821 & 4.00E-28 & $3.00 \mathrm{E}-25$ \\
\hline GO:0005737 & cytoplasm & 496 & 727 & 1.8976749 & 8.70E-28 & 3.30E-25 \\
\hline GO:0044444 & cytoplasmic part & 411 & 570 & 2.005587037 & $1.90 \mathrm{E}-26$ & 4.70E-24 \\
\hline GO:0032991 & macromolecular complex & 469 & 694 & 1.87969731 & 1.10E-25 & 2.00E-23 \\
\hline GO:0030529 & ribonucleoprotein complex & 259 & 294 & 2.450343564 & $3.50 \mathrm{E}-25$ & 5.20E-23 \\
\hline GO:0044424 & intracellular part & 852 & 1555 & 1.523995726 & 1.00E-23 & 1.30E-21 \\
\hline GO:0005840 & ribosome & 234 & 265 & 2.456091438 & $5.60 \mathrm{E}-23$ & $6.00 \mathrm{E}-21$ \\
\hline GO:0044464 & cell part & 1729 & 3696 & 1.301180597 & 4.30E-22 & 3.60E-20 \\
\hline GO:0005623 & cell & 1729 & 3696 & 1.301180597 & 4.30E-22 & $3.60 \mathrm{E}-20$ \\
\hline GO:0043229 & intracellular organelle & 657 & 1185 & 1.542132063 & 2.80E-19 & 1.90E-17 \\
\hline
\end{tabular}

${ }^{\mathrm{a}} \mathrm{FDR}$ false discovery rate was estimated by Benjamini-Hochberg-Yekutieli procedure at AgriGO (http://bioinfo.cau.edu.cn/agriGO/index.php)

which includes expansin and pectinesterase coding sequences, exhibited repressed transcription equally mediated by CS and GA (Fig. 5). The transcriptional profile of a large number of genes involved in cell wall processes in clusters IV, V and VI, remained virtually unchanged in response to both investigated factors (Fig. 5). In contrast, CS relieved the transcriptional repression of a subset of genes associated to cell wall metabolism in peach (cluster VII and VIII), including those related to carbohydrate metabolism and endomembrane transport (Fig. 5).
Genes associated to hormonal responses exhibit a more complex response pattern to GA exogenous application and CS in peaches (Fig. 6). A subset of transcripts corresponding to gibberellin biosynthesis oxidases and ethylene responsive transcription factors (AP2/ERF) (cluster I) was induced by CS, although subjected to an antagonistic effect of GA application (Fig. 6). A similar profile, although less marked, was observed for genes coding for auxin signaling partners and biosynthesis enzymes (cluster II and III). The combined action of cold storage and 


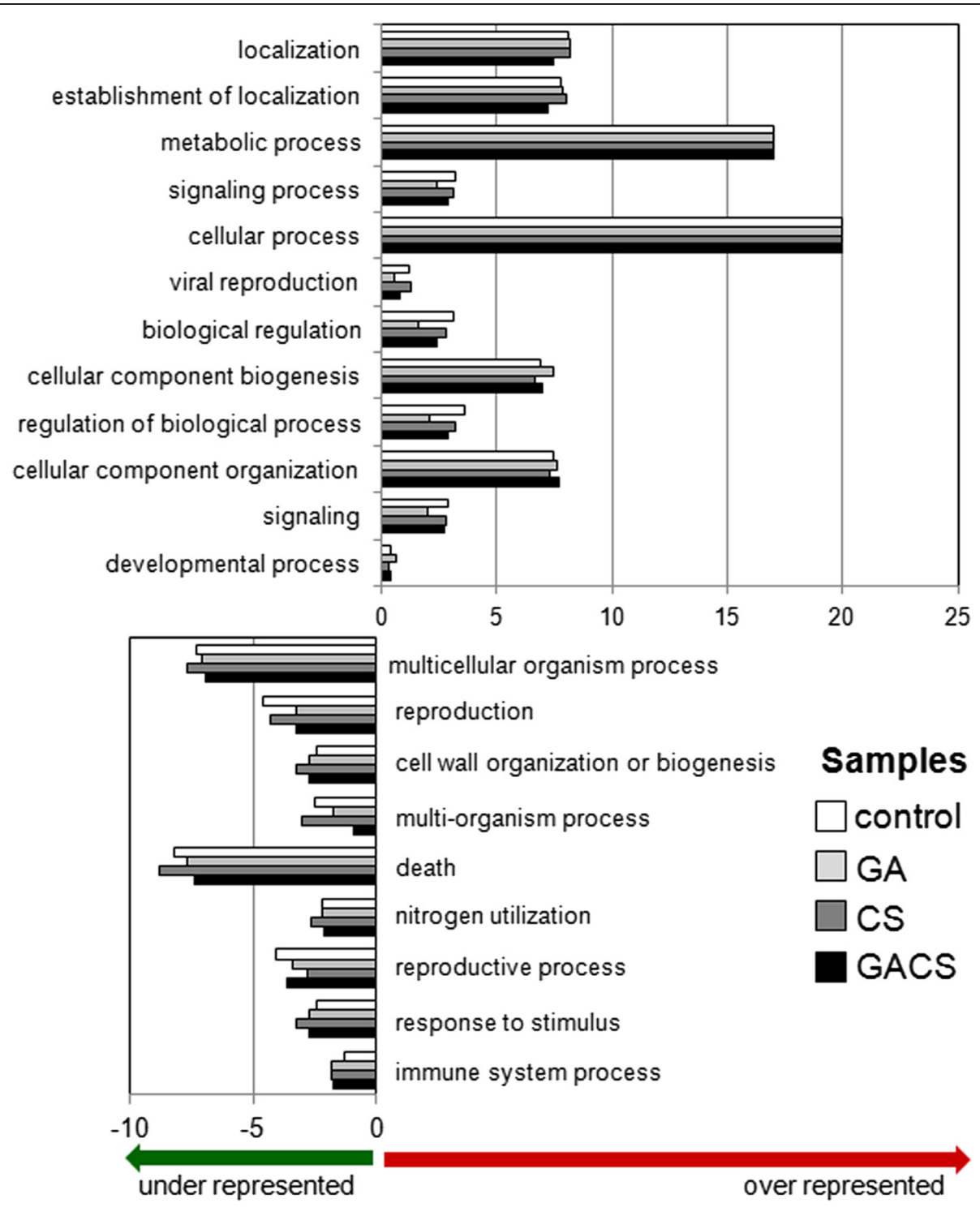

\section{Z-score of GO term}

Fig. 3 Singular enrichment analysis of GO biological process categories for differentially expressed genes. GO classifications of the responsive genes were compared to those from the peach genome and bar length represents z-score for the GO in each treatment. The treatments correspond to control (untreated fruits at harvest), GA (GA treated fruits at harvest), CS (untreated fruits submitted to cold storage) and GACS (GA treated fruits submitted to cold storage)

gibberellic acid treatment led to the repression of a small set of genes associated to hormone responses in cluster IV, with the majority of them belonging to the auxin, ethylene and gibberellin metabolism. In contrast, the transcription of other groups of hormone-related genes was repressed by CS with an inductive effect of GA (clusters V, VI and VII) (Fig. 6). Significant differential regulation was also observed for peach homologs of GA receptor GID1, one sequence coding for a DELLA repressor and ALCATRAZISPATULA transcription factor in response to CS and GA (Fig. 6). A small number of hormone associated genes were shown to respond individually to a single factor, with the vast majority of the sequences exhibiting transcriptional changes in response to both factors (Fig. 6). Corregulated modules consisting of GA, auxin and ethylene metabolism were evidenced by relevance network analysis, including a module of genes coding for auxin biosynthesis and signaling, GA catabolism and an ethylene responsive protein, auxin mediated signaling and ethylene responses and biosynthesis (Fig. 6). The opposite transcriptional behavior of the genes coding for GA and ethylene biosynthesis key enzymes in response to GA and CS was also shown (Fig. 6). In contrast, the transcription of sequences coding for auxin, GA and ethylene signaling 

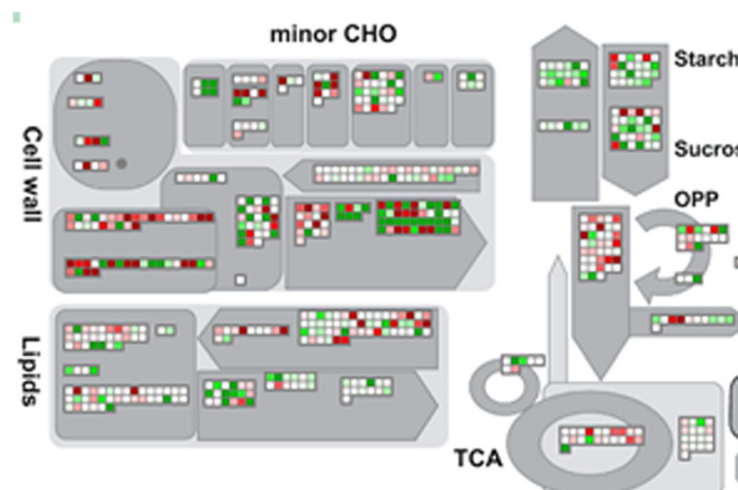

Ascortate, Givanion

Light
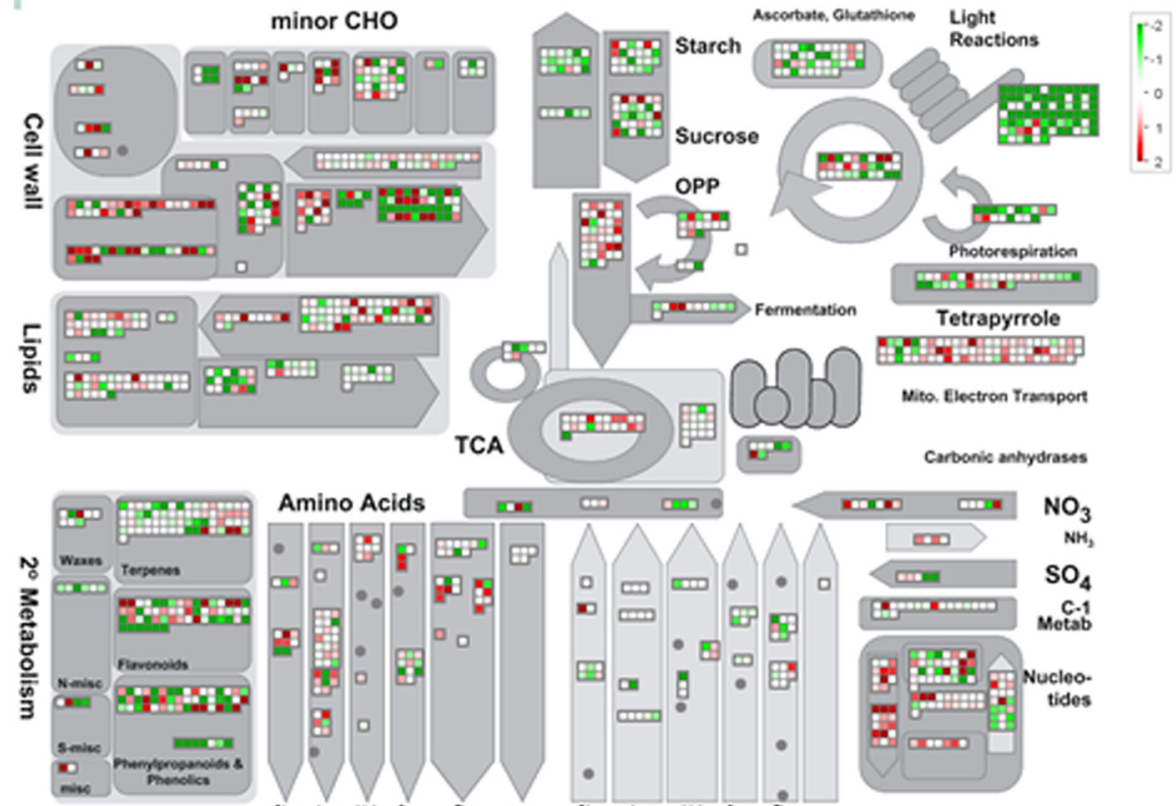

Amino Acids in cos cin

Bars:

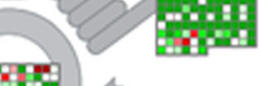

Honer

Photorespiration

Tetrapyrrole

Tetrapyrrole

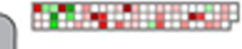

Wito. Electron Tramsport

Carbonic anhydrases

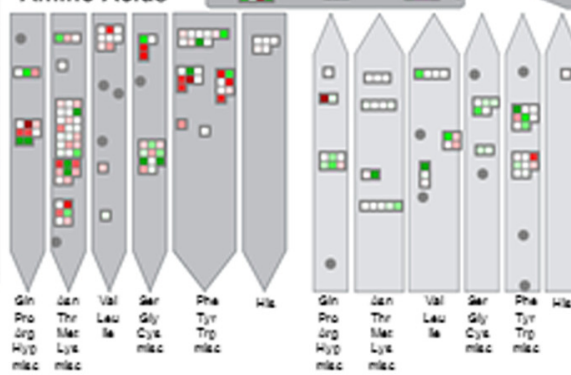

$000 \quad \mathrm{NO}_{3}$

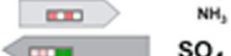

Pran

5. $\mathrm{Pan}$. Nucleo.

恶

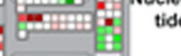

acro

ides

GA

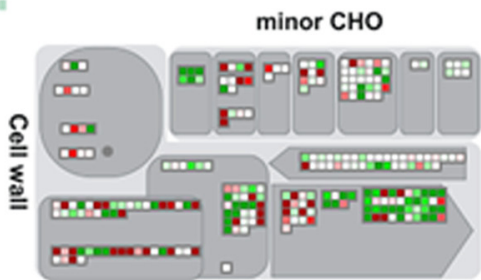

c

둘

Bin

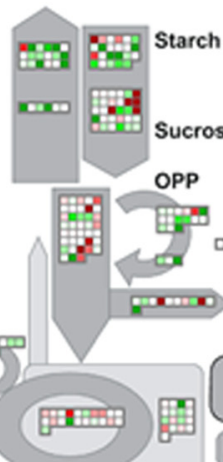

Ascorbate, Gluestion

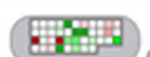
Reaction

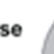

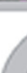

EसPF:
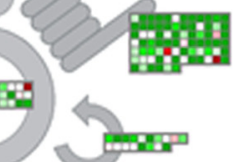

Photorespiration

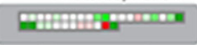

Tetrapyrrole

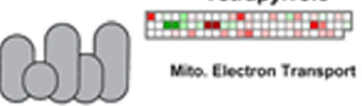

巴5

Carbonic anmydrases
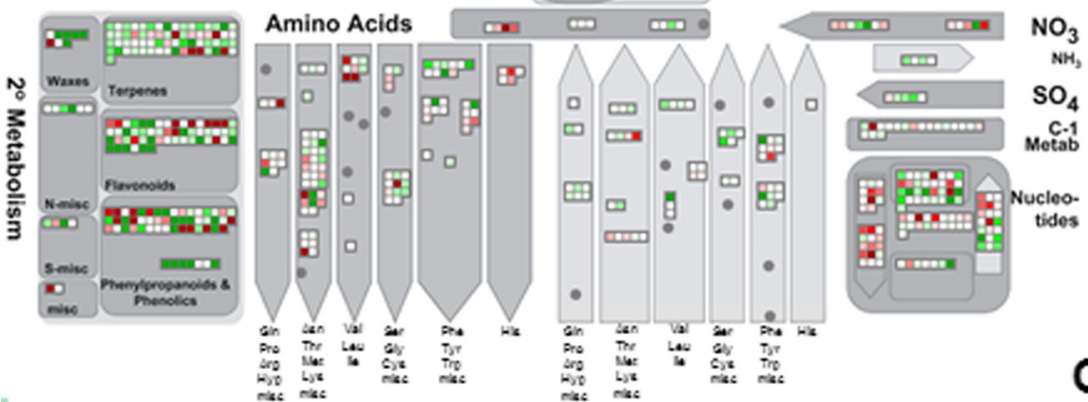

cs

Fig. 4 General metabolism classification of differentially expressed genes in response to GA and CS. The treatments used for determination of GA effect were $C$ (harvest) and CS - level GA 0 - against GA and GACS - level GA $50 \mathrm{mgL}^{-1}$. The treatments used for determination of CS effect were $C$ and GA - level CS 0 - against CS and GACS - level CS $0{ }^{\circ} \mathrm{C}$. Log $_{2}$ fold changes are represented as color scale for GA x no GA (a) and cold x no cold (b) contrasts. Positive values (red) correspond up regulated genes and negative values (green), to down regulated genes 


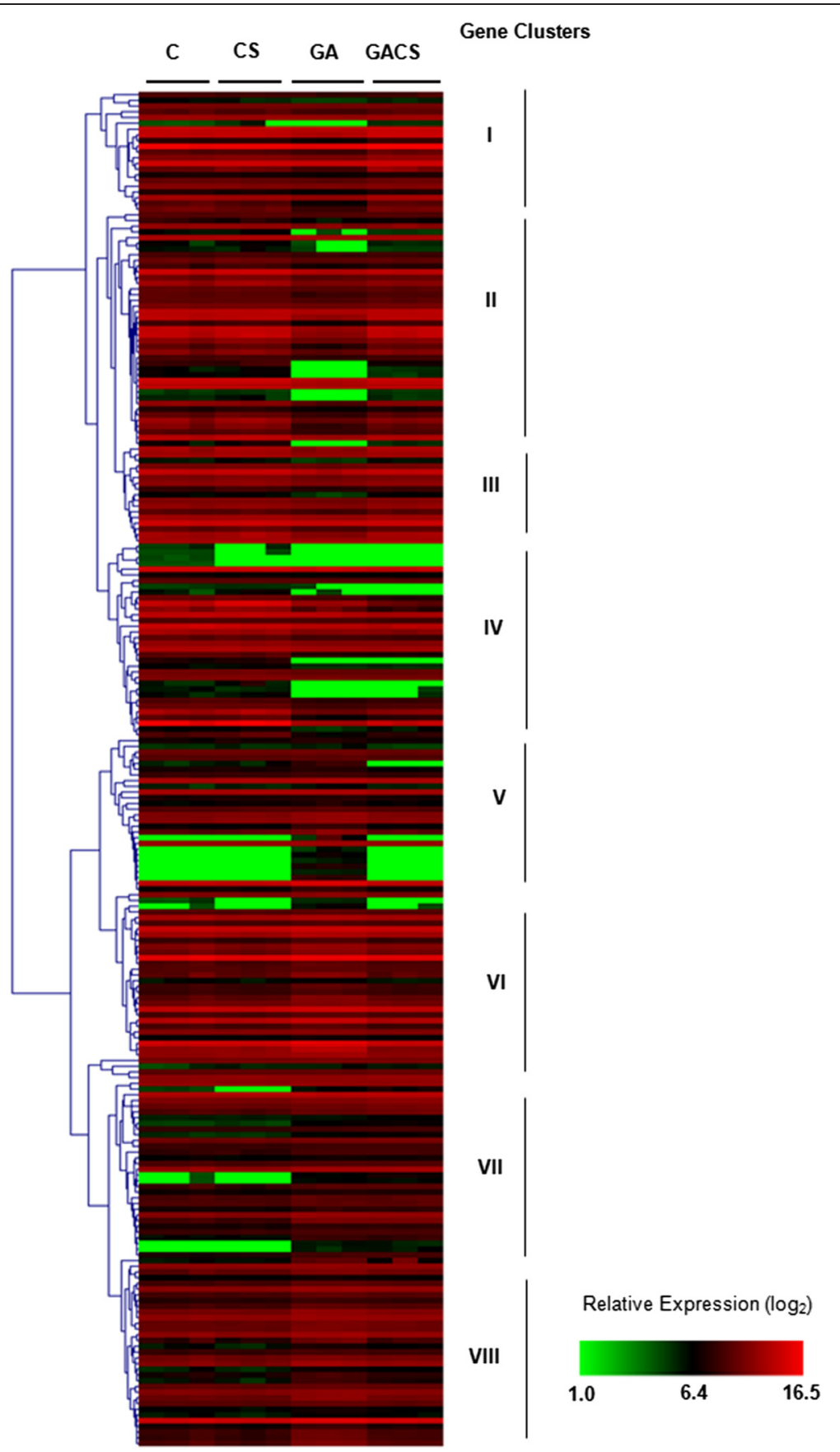

Fig. 5 Enrichment analysis of differentially expressed genes associated to cell wall metabolism in peach. Experimental conditions correspond to C (control fruits, 2 days at RT); CS (hormone untreated fruits, under cold storage for 15 days); GA (hormone treated fruits, 2 days at RT) and GACS (hormone treated fruits, under cold storage for 15 days). Roman numbers represent expression clusters, by Hierarchical Clustering using Pearson Correlation

partners exhibited a similar response to the investigated factors (Fig. 6).

\section{Reverse transcription quantitative PCR gene expression analyses}

Microarray data validation and time course expression analyses of candidate genes associated to woolliness under CS were performed by RT-qPCR. The expression patterns observed by microarray analyses were consistently confirmed by RT-qPCR for genes associated to cell wall metabolism, redox system and photosynthesis (Additional file 2: Figure S1). The expression pattern of approximately $70 \%$ of the investigated genes was similar between the microarray and RT-qPCR. 
A
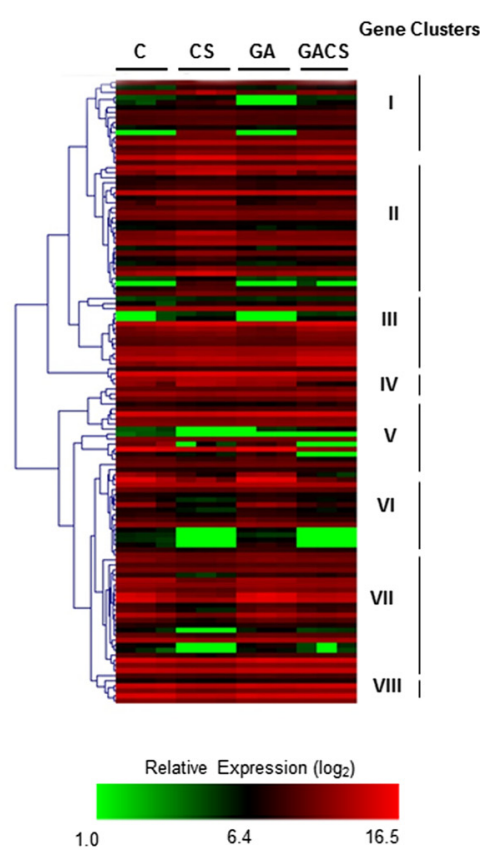

C

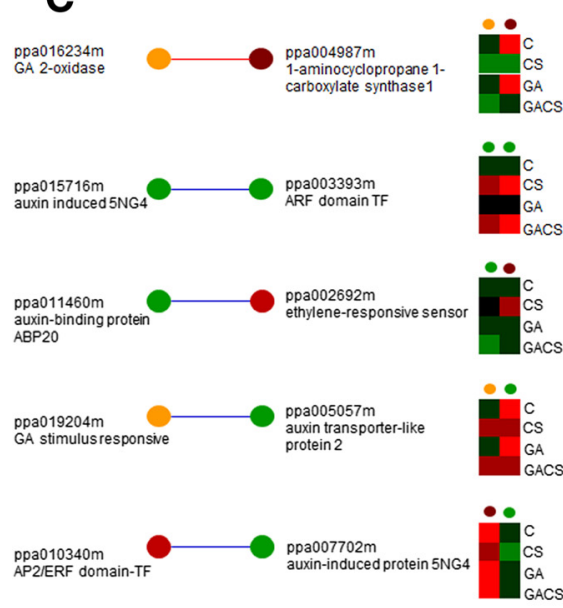

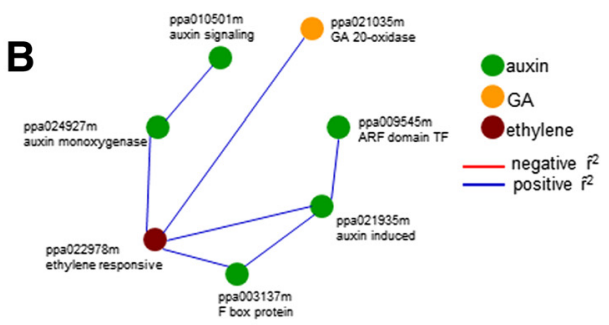
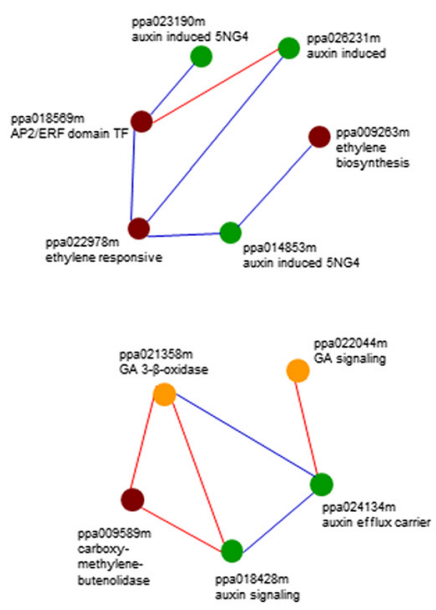

D

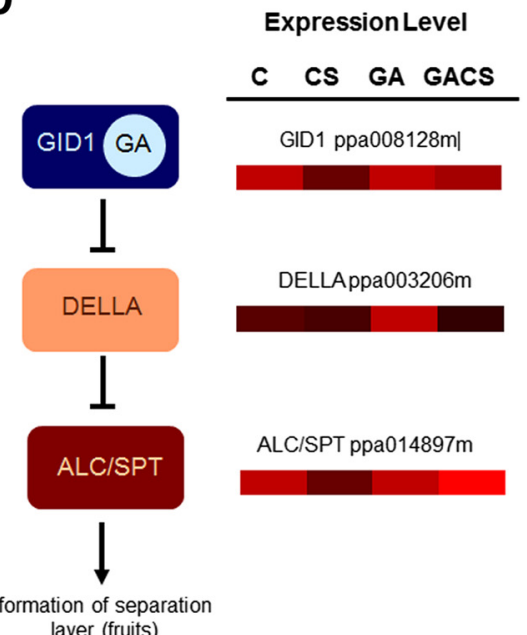

Fig. 6 a Enrichment analysis of differentially expressed genes associated to hormone metabolism in peach. Experimental conditions correspond to C (control fruits, 2 days at RT); CS (hormone untreated fruits, under cold storage for 15 days); GA (hormone treated fruits, 2 days at RT) and GACS (hormone treated fruits, under cold storage for 15 days). Roman numbers represent expression clusters, by Hierarchical Clustering using Pearson Correlation. b, $\mathbf{c}$ Relevance networks constructed from the expression pattern of genes associated to hormone metabolism. Associations with negative $\hat{\mathbf{r}}^{2}$ are represented in red and those with positive $\hat{\mathbf{r}}^{2}$, in blue. Probes with no associations at 0.80 were removed. $\mathbf{d}$ Expression of GA signaling components in endocarp layer separation in response to GA and CS

Time course analyses of cell wall metabolism genes during CS have demonstrated that the transcriptional profile of three genes associated to cell wall metabolism and one gene associated to photosynthesis were discrepant between control and GA treated fruit (Fig. 7). Interestingly, the most striking transcriptional differences between hormone treated and control fruit were found at the first half of the low temperature period for an EXPANSIN (EXP, ppa014051) coding sequence. In contrast, for PECTIN METHYL ESTERASE (PME, ppa005976) and POLYGALACTURONASE (PG, ppa025787m), the differences were greater at later stages of CS (Fig. 7). The 


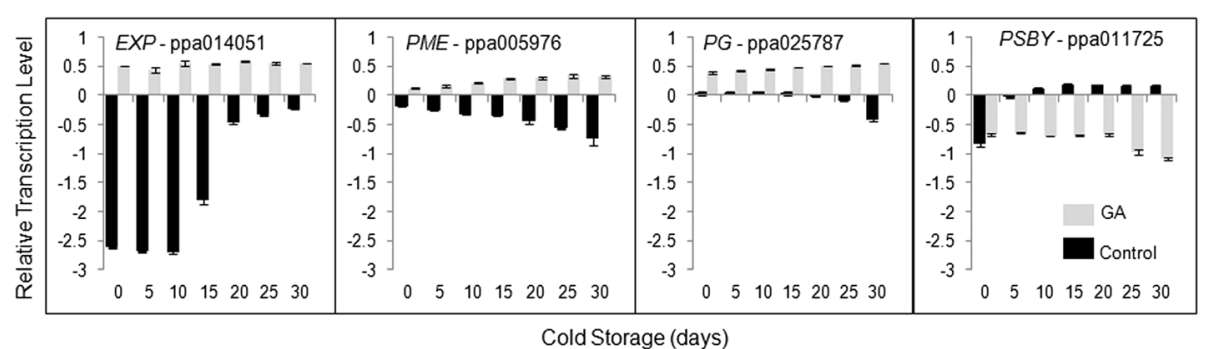

Fig. 7 Expression kinetics of cell wall metabolism and photosynthesis genes during CS and GA-treated peaches. Values correspond to the mean \pm SD $(n=3)$

transcription of a gene coding for a PHOTOSYSTEM II CORE COMPLEX PROTEIN (PSBY, ppa011725m) was repressed in GA treated fruit submitted to CS (Fig. 7).

\section{Discussion}

\section{Effect of GA application on peach fruit}

The role of GA in fruit ripening and development remains largely unknown, although the effect of endogenous or exogenous GA on fruit growth has been shown for several species $[19,20]$. Previously, we have demonstrated that exogenous application of GA at the initial stages of pit hardening effectively reduces the incidence of chilling injuries in responsive cultivars $[5,6]$. Applications at later stages did not significantly affect the frequency of the disorder in stored fruit $[5,6]$. Thus, the processes leading to reduced frequencies of woolliness in response to GA application are confined to pre lignification of the endocarp. In dry, dehiscent fruit of model plant Arabidopsis thaliana, GA has been demonstrated to negatively regulate, via DELLA repressors, the bHLH transcription factor ALCATRAZ (ALC), involved in the determination of the cell fate for the non-lignified valve margin tissues promoting fruit dehiscence [21, 22]. ALC function is partially redundant to that of another bHLH transcription factor, SPATULA (SPT) [23]. The transcriptional regulator INDEHISCENT (IND) activates the transcription of a GA-activating enzyme (GAOX1); thus, resulting in accumulation of the hormone in the separation valve layers leading to the dissociation of the DELLA repressor from ALC, allowing cell fate specification [22]. Recently, the essential role of gibberellinmediated signaling components in fruit development has been demonstrated for plum (Prunus salicina L.) [20].

Peach is a fleshy fruit with hardened endocarp, termed drupe. In peach genome clear homologs of $A L C$ and IND are absent and the most similar genes identified exhibit a non specific endocarp transcription pattern $[24,25]$. In contrast, the expression of peach SPT homo$\log$ is consistent with a role in cell fate determination in endocarp margins [26]. Thus, in peach, $S P T$ is likely to be an important factor controlling the determination of endocarp margins. Transcription of homologs of GA receptor GID1 and signaling components, including DELLA repressors and SPT transcription factor, was significantly altered by exogenous GA application and CS (Fig. 6). Interestingly, while all three components were repressed in response to CS and induced by GA application, the combination of both factors led to the induction of GID1 and SPT transcription (Fig. 6). The responsive DELLA coding sequence was down regulated by the combination of exogenous GA application and cold temperatures (Fig. 6). In other plant species the application of bioactive forms of gibberellin have been shown to stimulate the degradation of the repressive DELLA proteins and result in the loss of stress tolerance [27, 28]. Several corregulated modules consisting of genes associated to auxin, GA and ethylene metabolism were demonstrated by relevance network analyses of functionally annotated sequences (Fig. 6). Interestingly, exogenous GA application restored the expression levels of the key enzyme 1-aminocyclopropane 1-carboxylate synthase 1 (ACS1) of ethylene biosynthesis (Fig. 6). These observations suggest a role for CS in blocking ethylene biosynthesis and preventing woolliness in peach. Moreover, the transcriptional reprogramming of auxin biosynthesis and signaling genes in response to exogenous GA may indicate its involvement in the complex wooly phenotype of cold stored peaches. The extensive transcriptional changes observed in response to GA application (Fig. 2, Additional file 1: Table S1) and the overrepresentation of genes associated to cellular and developmental processes (Table 1, Fig. 3) and hormone metabolism (Fig. 6) in the genome wide transcriptional analyses indicate that reduced incidence of chilling induced damages is likely to result from extensive developmental reprogramming mediated by hormones in response to GA application.

\section{Effect of CS on peach fruit}

Low temperatures have been demonstrated to affect the activity of enzymes associated to pectin metabolism in fruit [2], although the magnitude and direction of the reported effects are largely discrepant [5, 11, 29-32]. In contrast to its biochemical effect, genome wide transcriptional analyses have demonstrated a preferential repressive function 
of low temperatures on gene expression in peach (Figs. 2, 4, 5 and 6). Low temperatures were also able to promote the transcription of a small number of genes associated to cell wall metabolism, and those related to carbohydrate metabolism and endomembrane transport (Fig. 4). Interestingly, the repressive effect of cold on gene expression was completely or partially alleviated by the exogenous application of GA for sequences associated to hormone metabolism and signal transduction, such as gibberellin biosynthesis oxidases and ethylene responsive transcription factors (AP2/ERF) (Fig. 6). Low temperatures had a significant repressive effect on the transcription of GA signaling components, although exogenous hormone application released the repression of GID1 and SPT homologs (Fig. 6).

In plants, the conserved C-repeat binding factor (CBF) pathway has been associated to low temperature tolerance in a wide range of evolutionary distinct species [33]. The CBF signaling network is positively regulated by the circadian clock components CCA1 and LHY [34] and functions downstream of the INDUCER OF CBF EXPRESSION 1 (ICE1) protein [33]. The hormone salicylic acid (SA) has also been shown to participate in low temperature responses in plants [35]. In peach, several genes exhibiting similarity to known partners of the $\mathrm{CBF}$ and SA pathway were transcriptionally affected by low temperatures (Fig. 6).

Our genome wide transcription profiling has demonstrated the antagonistic role of GA on low temperature transcriptional repression in fruit (Figs. 4, 5 and 6). These findings may be associated to the distinct functional roles of gibberellins throughout plant development, since the hormone is associated to stress tolerance during germination and seedling establishment [36] and is involved in stress sensitivity in determined vegetative tissues [37].

\section{The role of cell wall metabolism and hormone interplay in woolliness}

Woolliness is a complex phenotype observed in fruit after CS, consisting in a severe loss of juice and dry texture of the fruit flesh [2]. Peaches (Prunus persica Batsch.) and nectarines ( $P$. persica var. nectarina Ait.) are highly subjected to the physiological disorder [2, 3, 8], although some cultivars exhibit reduced woolliness incidence by exogenous GA application previous to pit hardening $[5,6]$. The reduction of polygalacturonase (PG) activity, and subsequent reduction in water-soluble pectins and increase in sodium-carbonate-soluble pectins, by low temperatures is considered the biochemical basis for woolliness in peaches [2]. Employing genome wide and time course expression analyses we have demonstrated that extensive transcriptional regulation occurs in stored peaches and may contribute to the biochemical changes that appear to underlie woolliness. Consistent with the reduced enzymatic activity, CS was demonstrated to preferentially repress gene expression in peach (Figs. 2, 4, 5, 6 and 7). Approximately, half of the peach transcriptome exhibited significant differential expression patterns in response to GA and CS, suggesting that extensive genetic reprogramming is the basis for the known biochemical changes during ripening.

The reduction in woolliness incidence by preharvest GA application to immature fruit, at early endocarp hardening stage is consistent with changes in the hormone mediated developmental transitions controlling ripening. In peach, low temperatures repressed the transcription of a GA receptor homolog GID1, a DELLA receptor coding sequence and an $A L C / S P T$ transcriptional regulator gene. In contrast, exogenous application of the hormone up regulated these genes. In GA treated fruits, chilling for 15 days restored the expression levels of GID1 and $A L C / S P T$, whereas the combination of GA and CS further decreased the transcription of the DELLA coding sequence. In Arabidopsis, there is no evidence of temperature regulation of the transcription of the partially redundant $A L C$ and $S P T[23,38,39]$. However, other members of the bHLH family of ALC and SPT, the PHYTOCHROME-INTERACTING FACTORS (PIFs), have been demonstrated to be involved in a wide range of temperature controlled processes in Arabidopsis [40-42].

Biochemical changes and modifications in enzyme activity are considered the most important mechanism responsible for chilling induced damage in peaches $[2,4,8]$. Our genome wide expression analyses suggest that transcriptional regulation is likely to contribute to the biochemical changes associated to postharvest processes in peach. Moreover, the over representation of genes associated to developmental ontology classes and the large number of hormone metabolism differentially regulated in response to CS and GA in peaches indicate that the physiological disorder and its reduced incidence in response to the hormone treatment are subjected to developmental regulation, as shown for other species [43-45]. In addition, genes related to photosystem I and II are differentially expressed in woolly fruit. These findings may contribute to explain the changes in chlorophyll a fluorescence during cold storage [46]. Transcript accumulation of PSBY is modified before chilling injury (after 15 days). Thus, the expression profile of the gene can be used as a wooliness incidence marker.

\section{Conclusion}

In the current work, we have investigated the factors underlying the prevention of chilling injuries in peaches by the application of GA at the initial stages of pit hardening, coupling physiological analyses of a responsive cultivar to global transcriptional profiling. We have confirmed the involvement of cell wall, hormone and stress metabolism in controlling the fruits responses to low temperatures during storage and have demonstrated that 
GA application at the early stages of endocarp hardening alone or coupled with cold storage trigger complex transcriptional reprogramming in peaches. Our data demonstrated the transcriptional control of GA receptor and signaling partner ALC/SPT in response to the hormone application and cold storage, suggesting GA controlled developmental processes, such as determination of endocarp borders, may be involved in the determination of chilling injury susceptibility in peach.

\section{Methods}

\section{Plant material}

Peach $[P$. persica (L.) Batsch cv. Chimarrita] fruits used in the current study were obtained from a commercial orchard of 'Chimarrita' clones grafted on 'Capdeboscq'. Permission to sample and harvest the fruits was requested before the experiments and granted by the orchard owner. 'Chimarrita' fruits have white, melting flesh that is semi-adherent to the endocarp, The ripening cycle is intermediate in Brazilian growth conditions, lasting 115 days from anthesis to fruit ripening. Three biological replicates, each consisting of 20 trees, were selected based on uniformity and conducted as follows: for GA treatment, plants were sprayed at $400 \mathrm{~L} \mathrm{ha}^{-1}$ of a solution of $50 \mathrm{mgL}^{-1}$ of GA (Pro-Gibb, Abbot Laboratories, North Chicago, USA, $10 \% \mathrm{~m} / \mathrm{m}$ ) supplemented with $0.05 \%(\mathrm{v} / \mathrm{v})$ surfactant (Silwet, Momentive Performance Materials Inc., Waterford, NY) pH 4.5, at the initial stage of the pit hardening (45 days after anthesis, DAA) (Additional file 3: Figure S2). Untreated control plants were sprayed with the solution without hormone. Fruits from treated and control plants were harvested at light green ground coloration, corresponding to the preclimacteric stage [6]. Each biological replicate consisted of 280 fruits (14 fruits from each tree), totalizing 840 fruits per treatment.

\section{Postharvest conditions}

Woolliness symptoms are distinguishable in peaches after two days at room temperature (RT, $25 \pm 2{ }^{\circ} \mathrm{C}$ ). Thus, analyses were performed after the 2-day RT period for all sampling points. Fruits were collected at harvest and up to 30 days under $\mathrm{CS}$ at $0 \pm 0.5{ }^{\circ} \mathrm{C}$ and $90 \pm 5 \%$ of relative humidity, at five day intervals. Experiments were conducted in triplicates, consisting of 40 fruits. Experimental design and sampling points are schematically represented in Additional file 3: Figure S2.

\section{Woolliness evaluation}

Incidence of woolliness was evaluated by manually squeezing the fruits, as described by Pegoraro et al. [6]. Fruits failing to release juice when squeezed were considered woolly. Normal distribution, homoscedasticity and residue independence of woolliness data were tested by Shapiro Wilk, Hartley test and graphic analyses, respectively. Data were subjected to $\mathrm{F}$ test $(\mathrm{p} \leq 0.05)$ ANOVA. Statistically significant results were compared by $t$ test $(\mathrm{p} \leq 0.05)$ for gibberellic acid and factor interaction effects, when present. Least significant differences (LSD) between the means were plotted and considered significant in the absence of overlapping vertical bars. Time course effects were investigated by non-linear regression models $(\mathrm{p} \leq 0.05)$, as follows: $\mathrm{y}=\mathrm{y} 0+\mathrm{ae}^{\mathrm{bx}}$, where: $y=$ response of interest variable; $y 0=$ minimal woolliness; $\mathrm{a}=$ maximum estimated value for the response variable; $\mathrm{b}=$ slope; $\mathrm{x}=$ time (days); $\mathrm{e}=$ constant.

\section{RNA extraction}

Samplings for genome wide transcriptional profiling were carried out at harvest and 15 days after CS (Additional file 3: Figure S2). This time point corresponds to the beginning of woolliness occurrence in untreated peaches. Total RNA extraction was carried out from $2 \mathrm{~g}$ of pulp, using a cetyltrimethylammonium bromide (CTAB) method described by Zeng Y, Yang [47]. Quantity and quality of the isolated RNA were spectrophotometrically analyzed with NanoDrop (NanoDrop, Thermo Scientific, Wilmington, DE), agarose gel and capillary electrophoresis using 2100 Bioanalyzer (Agilent Technologies, Santa Clara, CA). Hybridizations and qRTPCR experiments were performed with samples with RIN ranging from 8.5 to 9.3 [48]. Time course expression analyses during CS employed RNA extracted from $100 \mathrm{mg}$ of fruit pulp using PureLink kit (LifeTechnologies, Carlsbad, CA), as described by the manufacturer. Nucleic acid quality and quantity were determined as described previously. All samples were treated with DNase I (LifeTechnologies, Carlsbad, CA) for complete removal of genomic DNA, as confirmed by qPCR employing primers for TRANSLATION ELONGATION FACTOR 2 (TEF2) gene.

\section{Microarray hybridization}

Microarray hybridizations were performed for biological triplicates of each experimental treatment using the $\mu$ PEACH3.0 platform [49], with 1000 ng of total RNA for cDNA synthesis, following the protocol described by the manufacturer (Agilent Technologies, Santa Clara, $\mathrm{CA})$. Slides were scanned using the Agilent Scanner and fluorescence data was determined by Agilent Scan Control software following the manufacturer's instructions. Data were deposited in the Gene Expression Omnibus (GEO) database under accession number GSE71470.

\section{Microarray data analyses}

Microarray data produced by the Agilent microarray scanner were preprocessed by removal of spots considered 'well above background' by the Agilent pre-processing software (Agilent Feature Extraction Software). For each 
probe, intensity data of the two spots were averaged and quantile-normalized using R library 'preprocessCore' [50]. The quality of normalized data was assessed employing the LIMMA package [51] in $\mathrm{R}$ statistical programming language [51] at Bioconductor, by raw intensity box plots and density plots. Pairwise treatment conditions were compared by MA plots, where $\mathrm{M}=\log _{2}$ array $^{\mathrm{i}} / \mathrm{array}^{\mathrm{j}}$ and $\mathrm{A}=1$ / $2 * \log _{2}$ (array ${ }^{\mathrm{i} *}$ array $\left.{ }^{j}\right)$. Differential gene expression was analyzed using the LIMMA [51] and Gene Set Enrichment Analysis (GSEA) packages [52] at the Multi Experiment Viewer (MeV), EASE Expression Analysis Systematic Explorer version 4.9 software [53], employing a $2 \times 2$ factorial design on fruits at harvest and submitted to cold storage, with the factors being GA treatment (absent and present) and Cold Storage (present and absent).

The logical relations among the differentially expressed genes in the treatments were identified using the Venny software [54]. Differentially expressed genes were classified by ontology using singular enrichment analysis (SEA) and parametric analysis of gene set enrichment (PAGE) at AgriGo (http://bioinfo.cau.edu.cn/agriGO/index.php) and classified to metabolic pathways using MapMan v. 3.6 ORC1 software [55]. Relevance networks were constructed by comprehensively comparing all features with each other in a pair-wise manner over the treatments, using $\hat{r}^{2}$ [56].

\section{Reverse transcription quantitative PCR (RT-qPCR) expression analyses}

Time course analyses of gene expression during CS and microarray profile validations were performed by RTqPCR. Synthesis of cDNA was carried out from $1000 \mathrm{ng}$ of total RNA using Oligo d(T) (LifeTechnologies, Carlsbad, CA) primers and SuperScriptIII/RNAse Out Mix (LifeTechnologies, Carlsbad, CA), according to the manufacturer recommendations. Primers were designed for coding sequences of the candidate reference genes from the Prunus persica genome, available at the Genome Database for Rosaceae (GDR, - http://www.rosaceae.org/), using the default parameters of the software Primer3Plus [57]. Primer data are presented in Additional file 4: Table S2.

Primers were validated by amplification curve analyses employing a pool of cDNAs from all tested conditions, at five distinct concentrations. Oligonucleotide specificity and absence of primer dimers were checked by posttranscriptional dissociation curves. Quantitative PCR was carried at a StepOne ${ }^{\mathrm{TM}}$ Real Time PCR System (LifeTechnologies, Carlsbad, CA) and the SYBR ${ }^{\mathrm{TM}}$ Green PCR Master Mix (LifeTechnologies, Carlsbad, CA). The reactions started with a denaturation step at $95^{\circ} \mathrm{C}$ for $10 \mathrm{~min}$, followed by 40 cycles consisting of $15 \mathrm{~s}$ at $95^{\circ} \mathrm{C}$ and $1 \mathrm{~min}$ at $60{ }^{\circ} \mathrm{C}$, finalized by the dissociation curve with denaturation at $95{ }^{\circ} \mathrm{C}$ for $15 \mathrm{~s}$, cooling at $60{ }^{\circ} \mathrm{C}$ for $1 \mathrm{~min}$ and gradual heating, at $0.3{ }^{\circ} \mathrm{C}$ steps, up to $95{ }^{\circ} \mathrm{C}$. A negative, no template control (NTC), was used to confirm the absence of genomic DNA. Expression data were normalized employing RNA POLYMERASE II (RP II), UBIQUITIN C $(U B C)$ and TEF2 as reference genes and calibrated using samples from fruits kept at RT for two days after harvest, which are considered optimum for human consumption.

\section{Availability of supporting data}

The data set supporting the results of this article is included within the article and its additional files. Microarray hybridization data were deposited in the Gene Expression Omnibus (GEO) database under accession number GSE71460.

\section{Additional files}

Additional file 1: Table S1. Genes exhibiting significant differential expression in peach. Analyses were performed as a factorial $2 \times 2$ design, using the LIMMA (Linear Models for Microarray and RNAseq Data) package (Smyth, 2005) at Bioconductor. (XLSX 4527 kb)

Additional file 2: Figure S1. Expression validation of microarray genes by RT-qPCR for cold stored and GA treated fruits. Represented genes are functionally classified to cell wall metabolism (EXP - ppa014051m, PME ppa005976m and PG - ppa025787m), photosynthesis light reactions (PSBY - ppa011725m, PSI-L - ppa011229m and PSI-RC - ppa010953m) and redox metabolism (APX - ppa010426m, SOD - ppa009729m and GPX -

ppa011681m). Values correspond to the mean \pm SD $(n=3)$. (PDF $127 \mathrm{~kb})$

Additional file 3: Figure S2. Schematic representation of the fruit sampling points used in the current study. Sampling of the fruits for molecular and sensory analyses started after two days at room temperature (RT). Triangles represent sampling points for wooliness detection (black), microarray hybridizations (white) and time course expression analyses by RT-qPCR (spotted). (PDF $118 \mathrm{~kb}$ )

Additional file 4: Table S2. Peach (Prunus persica (L.) Batsch.) genome and amplification information on the RT-qPCR primers used in the current study. (PDF $73 \mathrm{~kb}$ )

\section{Abbreviations}

ACS: 1-aminocyclopropane 1-carboxylate synthase 1; ALC: ALCATRAZ;

ANOVA: analysis of variance; AP2/ERF: APETALA2/ethylene responsive factor; bHLH: basic helix-loop-helix; CBF: C-repeat binding factor; CCA1: circadian clock associated 1; CDNA: complementary DNA; CS: cold storage; CSGA: cold storage_ gibberellic acid; CTAB: cetyltrimethylammonium bromide; DAA: days after anthesis; DELLA: DELLA protein; DNA: deoxyribonucleic acid; EASE: expression analysis systematic explorer; EXP: expansin; GA: gibberellic acid; GAOX1: gibberellin oxidase1; GDR: genome database for rosaceae; GID1: gibberellin insensitive dwarf1; GO: gene ontology; GSEA: gene set enrichment analyses; ICE1: inducer of CBF expression; IND: indehiscent; LHY: late elongated hypocotyl; LIMMA: linear models for microarray data; LSD: least significant differences; MeV: multi experiment viewer; NTC: no template control; PAGE: parametric analysis of gene set enrichment; PG: polygalacturonase; PIFs: phytochrome-interacting factors; PME: pectin methyl esterase; PSBY: photosystem II core complex protein; RNA: ribonucleic acid; RP II: RNA polymerase II; RT: room temperature; RT-qPCR: reverse transcription-quantitative polymerase chain reaction; SA: salicylic acid; SEA: singular enrichment analysis; SPT: SPATULA; TEF2: TRANSLATION ELONGATION FACTOR 2; UBC: UBIQUITIN C.

\section{Competing interests}

The authors declare that they have no competing interests.

\section{Authors' contributions}

$C P, A C O, C V R$ participated in the design of the study, analyses and helped to draft the manuscript. CP, AT and VQ performed the microarray studies, interpreted bioinformatic results, and drafted the manuscript. CP, AT, CLG, FCC, VQ, ACO, LT and CVR participated in the design of the study and in the 
microarray data interpretation. CP, AT, CLG, FCC, VQ, ACO, LT and CVR interpreted statitics and bioinformatic results, and drafted the manuscript. All authors read and approved the final manuscript.

\section{Acknowledgements}

The authors would like to thank Coordenação de Aperfeiçoamento de Pessoal de Nível Superior (CAPES) for scholarships and Conselho Nacional de Desenvolvimento Científico e Tecnológico (CNPq) for research funding, scholarships and for financing study missions abroad. LT acknowledges the support by Ministero delle Politiche Agricole Alimentari e Forestali - Italy (MiPAAF, www.politicheagricole.it) via the project "DRUPOMIC" (grant DM14999/7303/08).

\section{Author details}

'Plant Genomics and Breeding Center, Universidade Federal de Pelotas, Campus UFPel Capão do Leão, Pelotas, RS 96010-900, Brazil. ${ }^{2}$ Current Address: Embrapa Uva e Vinho, Rua Livramento 515, Bento Gonçalves, RS 95700-000, Brazil. ${ }^{3}$ Department of Biology, University of Padova, Viale G. Colombo, Padova 3, 35121, Italy. ${ }^{4}$ Current Address: Research and Innovation Centre, Fondazione Edmund Mach, Via Mach 1, San Michele all'Adige, Trento 38010, Italy. ${ }^{5}$ Embrapa Uva e Vinho, Rua Livramento 515, Bento Gonçalves, RS 95700-000, Brazil. ' ${ }^{6}$ epartament of Food Science and Technology, Universidade Federal de Pelotas, Campus UFPel Capão do Leão, Pelotas, RS 96010-900, Brazil.

Received: 31 July 2015 Accepted: 3 November 2015 Published online: 18 November 2015

\section{References}

1. Prinsi B, Negri AS, Fedeli C, Morgutti S, Negrini N, Cocucci M, et al. Peach fruit ripening: a proteomic comparative analysis of the mesocarp of two cultivars with different flesh firmness at two ripening stages. Phytochemistry. 2011;72:1251-62.

2. Fruk G, Cmelik Z, Jemric T, Hribar J, Vidrih R. Pectin role in woolliness development in peaches and nectarines: a review. Sci Hortic. 2014;180:1-5.

3. Lurie $\mathrm{S}$, Crisosto $\mathrm{CH}$. Chilling injury in peach and nectarine. Postharvest Biol Technol. 2005;37:195-208.

4. Lurie S, Vanoli M, Dagar A, Weksler A, Lovati F, Eccher Zerbini PC, et al. Chilling injury in stored nectarines and its detection by time-resolved reflectance spectroscopy. Postharvest Biol Technol. 2011;59:211-8.

5. Pegoraro C, Zanuzo MR, Chaves FC, Brackmann A, Girardi CL, Lucchetta L, et al. Physiological and molecular changes associated with prevention of woolliness in peach following pre-harvest application of gibberellic acid. Postharvest Biol Technol. 2010;57:19-26.

6. Pegoraro C, Chaves FC, Cero JD, Girardi CL, Rombaldi CV. Effects of preharvest gibberellic acid spraying on gene transcript accumulation during peach fruit development. Plant Growth Regul. 2011;65:231-7.

7. Wp X, Zhang B, Shen J, Sun C, Xu C, Chen K. Intermittent warming alleviated the loss of peach fruit aroma-related esters by regulation of AAT during cold storage. Postharvest Biol Technol. 2012;74:42-8.

8. Arana I, Jarén C, Arazuri S. Nectarine woolliness detection by non-destructive mechanical impact. Biosyst Eng. 2005;90:37-45.

9. Pons Puig C, Dagar A, Marti Ibanez C, Singh V, Crisosto CH, Friedman H, et al. Pre-symptomatic transcriptome changes during cold storage of chilling sensitive and resistant peach cultivars to elucidate chilling injury mechanisms. BMC Genomics. 2015;16:245.

10. Goldberg-Moeller R, Shalom L, Shlizerman L, Samuels S, Zur N, Ophir R, et al. Effects of gibberellin treatment during flowering induction period on global gene expression and the transcription of flowering-control genes in Citrus buds. Plant Sci. 2013;198:46-57.

11. González-Agüero M, Pavez L, Ibáñez F, Pacheco I, Campos-Vargas R, Meisel $L A$, et al. Identification of woolliness response genes in peach fruit after post-harvest treatments. J Exp Bot. 2008;59:1973-86.

12. Nilo R, Saffie C, Lilley K, Baeza-Yates R, Cambiazo V, Campos-Vargas R, et al. Proteomic analysis of peach fruit mesocarp softening and chilling injury using difference gel electrophoresis (DIGE). BMC Genomics. 2010;11:43.

13. Ogundiwin EA, Martí C, Forment J, Pons C, Granell A, Gradziel TM, et al. Development of ChillPeach genomic tools and identification of cold-responsive genes in peach fruit. Plant Mol Biol. 2008;68:379-97.

14. Vizoso P, Meisel LA, Tittarelli A, Latorre M, Saba J, Caroca R, et al. Comparative EST transcript profiling of peach fruits under different post-harvest conditions reveals candidate genes associated with peach fruit quality. BMC Genomics. 2009;10:423.

15. Pavez L, Hödar C, Olivares F, González M, Cambiazo V. Effects of postharvest treatments on gene expression in Prunus persica fruit: Normal and altered ripening. Postharvest Biol Technol. 2013;75:125-34.

16. Sánchez G, Venegas-Calerón M, Salas JJ, Monforte A, Badenes ML, Granell A. An integrative "omics" approach identifies new candidate genes to impact aroma volatiles in peach fruit. BMC Genomics. 2013;14:343.

17. Tosetti R, Tardelli F, Tadiello A, Zaffalon V, Giorgi FM, Guidi L, et al. Molecular and biochemical responses to wounding in mesocarp of ripe peach (Prunus persica L. Batsch) fruit. Postharvest Biol Technol. 2014;90:40-51.

18. Cruz-Mendívil A, López-Valenzuela JA, Calderón-Vázquez CL, Vega-García MO, Reyes-Moreno C, Valdez-Ortiz A. Postharvest biology and technology transcriptional changes associated with chilling tolerance and susceptibility in "Micro-Tom" tomato fruit using RNA-Seq. Postharvest Biol Technol. 2015;99:141-51.

19. Serrani JC, Sanjuán R, Ruiz-Riveiro O, Fos M, García-Martínez JL. Gibberellin regulation of fruit set and growth in tomato. Plant Physiol. 2007;145:246-57.

20. El-Sharkawy I, Sherif S, El Kayal W, Mahboob A, Abubaker K, Ravindran P, et al. Characterization of gibberellin-signalling elements during plum fruit ontogeny defines the essentiality of gibberellin in fruit development. Plant Mol Biol. 2014:84:399-413.

21. Sorefan K, Girin T, Liljegren SJ, Ljung K, Robles P, Galván-Ampudia CS, et al. A regulated auxin minimum is required for seed dispersal in Arabidopsis. Nature. 2009;459:583-6.

22. Arnaud N, Girin T, Sorefan K, Fuentes S, Wood TA, Lawrenson T, et al. Gibberellins control fruit patterning in Arabidopsis thaliana. Genes Dev. 2010;24:2127-32

23. Groszmann M, Paicu T, Alvarez JP, Swain SM, Smyth DR. SPATULA and ALCATRAZ, are partially redundant, functionally diverging $b H L H$ genes required for Arabidopsis gynoecium and fruit development. Plant J. 2011;68:816-29.

24. Dardick CD, Callahan AM, Chiozzotto R, Schaffer RJ, Piagnani MC, Scorza R. Stone formation in peach fruit exhibits spatial coordination of the lignin and flavonoid pathways and similarity to Arabidopsis dehiscence. BMC Biol. 2010;8:13.

25. Dardick C, Callahan AM. Evolution of the fruit endocarp: molecular mechanisms underlying adaptations in seed protection and dispersal strategies. Front Plant Sci. 2014;5:284.

26. Tani E, Tsaballa A, Stedel C, Kalloniati C, Papaefthimiou D, Polidoros A, et al. The study of a SPATULA-like bHLH transcription factor expressed during peach (Prunus persica) fruit development. Plant Physiol Biochem. 2011;49:654-63.

27. Achard P, Gong F, Cheminant S, Alioua M, Hedden P, Genschik P. The cold-inducible CBF1 factor-dependent signaling pathway modulates the accumulation of the growth-repressing DELLA proteins via its effect on gibberellin metabolism. Plant Cell. 2008;20:2117-29.

28. Davière JM, de Lucas M, Prat S. Transcriptional factor interaction: a central step in DELLA function. Curr Opin Genet Dev. 2008;18:295-303.

29. Ben-Arie R, Sonego L. Pectolytic enzyme activity involved in woolly breakdown of stored peaches. Phytochemistry. 1980;19:2553-5.

30. Zhou H, Sonego L, Khalchitski A, Ben-Arie R, Lers A, Lurie S. Cell wall enzymes and cell wall changes in "flavortop" nectarines: mRNA abundance, enzyme activity, and changes in pectic and neutral polymers during ripening and in woolly fruit. Enzyme. 2000;125:630-7.

31. Obenland DM, Carroll TR. Mealiness and pectolytic activity in peaches and nectarines in response to heat treatment and cold storage. J Am Soc Hortic Sci. 2000;125:723-8.

32. Brummell DA, Cin VD, Lurie S, Crisosto CH, Labavitch JM. Cell wall metabolism during the development of chilling injury in cold-stored peach fruit: association of mealiness with arrested disassembly of cell wall pectins. J Exp Bot. 2004;55:2041-52.

33. Thomashow MF. Molecular basis of plant cold acclimation: insights gained from studying the CBF cold response pathway. Plant Physiol. 2010;154:571-7.

34. Dong MA, Farré EM, Thomashow MF. Circadian clock-associated 1 and late elongated hypocotyl regulate expression of the C-repeat binding factor (CBF) pathway in Arabidopsis. Proc Natl Acad Sci U S A. 2011;108:7241-6.

35. Miura K, Ohta M. SIZ1, a small ubiquitin-related modifier ligase, controls cold signaling through regulation of salicylic acid accumulation. J Plant Physiol. 2010;167:555-60.

36. Nasri N, Kaddour R, Rabhi M, Plassard C, Lachaal M. Effect of salinity on germination, phytase activity and phytate content in lettuce seedling. Acta Physiol Plant. 2011;33:935-42. 
37. Achard P, Cheng H, De Grauwe L, Decat J, Schoutteten H, Moritz T, et al. Integration of plant responses to environmentally activated phytohormonal signals. Science. 2006;311:91-4.

38. Vaistij FE, Gan Y, Penfield S, Gilday AD, Dave A, He Z, et al. Differential control of seed primary dormancy in Arabidopsis ecotypes by the transcription factor SPATULA. Proc Natl Acad Sci U S A. 2013;110:10866-71.

39. Josse EM, Gan Y, Bou-Torrent J, Stewart KL, Gilday AD, Jeffree CE, et al. A DELLA in disguise: SPATULA restrains the growth of the developing Arabidopsis seedling. Plant Cell. 2011;23:1337-51.

40. Yamashino T, Nomoto Y, Lorrain S, Miyachi M, Ito S, Nakamichi N, et al. Verification at the protein level of the PIF4-mediated external coincidence model for the temperature-adaptive photoperiodic control of plant growth in Arabidopsis thaliana. Plant Signal Behav. 2013;8, e23390.

41. Bours R, Kohlen W, Bouwmeester HJ, van der KA. Thermoperiodic control of hypocotyl elongation depends on auxin induced ethylene signaling which controls downstream phytochrome interacting factor 3 activity. Plant Physiol. 2015;167:517-30.

42. Johansson H, Jones HJ, Foreman J, Hemsted JR, Stewart K, Grima R, et al. Arabidopsis cell expansion is controlled by a photothermal switch. Nat Commun. 2014;5:1-8.

43. Acheampong AK, Hu J, Rotman A, Zheng C, Halaly T, Takebayashi Y, et al. Functional characterization and developmental expression profiling of gibberellin signalling components in Vitis vinifera. J Exp Bot. 2015;66:1463-76.

44. Azzi L, Deluche C, Gévaudant F, Frangne N, Delmas F, Hernould M, et al. Fruit growth-related genes in tomato. J Exp Bot. 2015;66:1075-86.

45. Karlova R, Chapman N, David K, Angenent GC, Seymour GB, De Maagd RA Transcriptional control of fleshy fruit development and ripening. J Exp Bot. 2014;65:4527-41.

46. Wright AH, DeLong JM, Gunawardena AHLAN, Prange RK. Dynamic controlled atmosphere (DCA): does fluorescence reflect physiology in storage? Postharvest Biol Technol. 2012;64:19-30.

47. Zeng Y, Yang T. RNA isolation from highly viscous samples rich in polyphenols and polysaccharides. Plant Mol Biol Report. 2002;20:417.

48. Schroeder A, Mueller O, Stocker S, Salowsky R, Leiber M, Gassmann M, et al. The RIN: an RNA integrity number for assigning integrity values to RNA measurements. BMC Mol Biol. 2006;7:3.

49. Trainotti L, Cagnin S, Forcato C, Bonghi C, Dhingra A, Koepke T, et al. Functional genomics: transcriptomics. In: Kole C, Abbott AG, editors. Genetics genomics and breed of stone fruits. Boca Raton; CRC Press, Taylor \& Francis Group: 2012. p. 292-322.

50. Bolstad BM, Irizarry RA, Astrand M, Speed TP. A comparison of normalization metholds for high density oligonucleotide array data based on variance and bias. Bioinformatics. 2003;19:185-93.

51. Smyth GK. Limma: linear models for microarray data. In: Gentleman WHR, Carey V, Dudoit S, Irizarry R, editors. Bioinformatics and computational biology solutions using R and bioconductor. Springer, New York; 2005:397-20.

52. Subramanian A, Tamayo P, Mootha VK, Mukherjee S, Ebert BL, Gillette MA, et al. Gene set enrichment analysis: a knowledge-based approach for interpreting genome-wide expression profiles. Proc Natl Acad Sci U S A. 2005;102:15545-50.

53. Saeed Al, Sharov V, White J, Li J, Liang W, Bhagabati N, et al. TM4: a free, open-source system for microarray data management and analysis. Biotechniques. 2003;34:374-8.

54. Oliveros J. An interactive tool for comparing lists with Venn Diagrams. 2007.

55. Thimm O, Bläsing O, Gibon Y, Nagel A, Meyer S, Krüger P, et al. MapMan: a user-driven tool to display genomics data sets onto diagrams of metabolic pathways and other biological processes. Plant J. 2004;37:914-39.

56. Butte AJ, Tamayo P, Slonim D, Golub TR, Kohane IS. Discovering functional relationships between RNA expression and chemotherapeutic susceptibility using relevance networks. Proc Natl Acad Sci U S A. 2000;97(22):12182-6.

57. Untergasser A, Nijveen $H$, Rao X, Bisseling T, Geurts R, Leunissen JA. Primer3Plus, an enhanced web interface to Primer3. Nucleic Acids Res. 2007:35:71-4.

\section{Submit your next manuscript to BioMed Central and take full advantage of:}

- Convenient online submission

- Thorough peer review

- No space constraints or color figure charges

- Immediate publication on acceptance

- Inclusion in PubMed, CAS, Scopus and Google Scholar

- Research which is freely available for redistribution

Submit your manuscript at www.biomedcentral.com/submit 